\title{
OPTICAL AND COLORIMETRICAL CHARACTERISTICS OF STRAINED LiF CRYSTALS UNDER X-RAY IRRADIATION
}

\author{
O.M. Petchenko, G.O. Petchenko, S.M. Boiko, A.V. Bezugly \\ O.M. Beketov Kharkiv National University of Urban Economy, \\ Kharkiv, Ukraine \\ E-mail: gdaeron@ukr.net
}

Here there were investigated the $\mathrm{x}$-irradiation influence on the optical characteristics of LiF crystals and the colorimetric characteristics of optical radiation passing through crystals with different doses of irradiation. It was established that change of irradiation dose in the interval $0 \ldots 1057 \mathrm{P}$ leads to reduce of absolute value of coordinates of the color and brightness of the radiation, passing through the crystal, but the color of the radiation thus remains constant.

\section{INTRODUCTION}

This work is the continuation of a papers [1, 2], aimed at studying the nature of radiation defects in $\mathrm{LiF}$ single crystals with different mechanical stages. Works $[1,2]$, in turn, complement works in $\mathrm{LiF}$ [3-8] and others [9-23], where the influence of structural defects on the course of phonon-dislocation interaction processes in other crystals was studied. In works $[1,2]$ an optical absorption method was used, which, unlike acoustic [3-23], allows to carry out quantitative and qualitative analysis of effective centers of radiation origin fastening at dislocations. It is known [24-26] that when the crystal is exposed to X-ray irradiation, the main part of its energy is spent on the creation of electronic excitations. In the presence of these excitations in the vicinity of anion vacancies, due to the localization of electrons on them, appear electron color centers. In the simplest case, these are F-centers [25], then, with the accumulation of the radiation dose in the crystal, the combination of F-centers into more complex units are possible. For example, if there are two adjacent F-centers, $F_{2}(M)$ centers appear, three $-\mathrm{F}_{3}(\mathrm{R})$-centers and etc. To study the mentioned and other types of radiation defects the absorption method [24] is widely used. It is based on measuring of dependences from the wavelength of the spectral transmittance index $\tau_{\lambda}(\lambda)$ in the UV and visible range of the spectrum. Having the color centers in the crystal at the specified dependences, the areas where transmission is minimal have been traced - namely, the so-called absorption bands. From the data on the absorption band (in particular, its localization on the wavelength axis) information about the type of defect as well as their amount has been obtained. It should also be emphasized that the most convenient of ionic crystals for optical studies are crystals $\mathrm{LiF}$, in which color centers are highly resistant to photoexcitation and are stored at room temperature for a long time [25].

It is known that LiF single crystals, besides being model, and therefore, rather convenient for testing the existing theories, are quite attractive from the practical point of view. They are used in detectors and dosimeters of ionizing radiation, in electrical circuits - for the delay of electrical signals, it is known [27] about their use in laser technology, medicine and radiobiology. In addition, LiF crystals are widely used in optics, particularly in X-ray optics as crystal monochromators.
When using LiF crystals in optical devices as functional materials, it is important to know, how external factors will affect their optical characteristics. It is known that one of the key Units of an optical device is a radiation receiver. At the design stage, the receiver is selected for spectral sensitivity in a visible region of the spectrum to perform the specific research tasks. It is assumed that the spectral composition of radiation passing through the optical system of the device remains unchanged, and the receiver response is predictable and effective. With variations in the color of the radiation, due to irradiation changes in functional materials, a decrease in the efficiency of radiation registration by an optical device can be observed.

The purpose of this work is to determine the effect of ionizing radiation on the color characteristics of the rays in visible region of the spectrum passing through the crystal, which acts as light filter.

\section{MATERIALS AND METHODS OF THE RESEARCH}

For the experiment, the samples $\mathrm{LiF}$ with residual deformations $\varepsilon=3.3 \%$ and the size of approximately $18 \times 19 \times 27 \mathrm{~mm}$ have been used [1]. The purity of the crystals was $10^{-4} \mathrm{wt} . \%$. After reaching the preliminary sizes, samples were grounded and polished to achieve the level of plane parallel $\pm 1 \mu \mathrm{m} / \mathrm{cm}$ that was controlled by the IKV optimeter. To eliminate the internal stresses resulting from mechanical treatment, the test specimens were annealed in a muffle furnace MP-2UM for about $12 \mathrm{~h}$ at a temperature close to the melting point of the crystal $T \sim 0.8 T_{\text {melt }}\left(T_{\text {melt }}=870{ }^{\circ} \mathrm{C}\right)$, followed by slow cooling to room temperature. The preliminary deformation of the samples was carried out on a machine of the type "Instron" at a deformation rate of $\sim 10^{-5} \mathrm{~s}^{-1}$ by compression along the crystallographic direction $\langle 100\rangle$. Control over the achievement of the required value of $\varepsilon$ was ensured by accurately recording the moment of the crystal's output to the yield point with a mark on the tape of the recorder KSP-4, and the change in the length of the samples was controlled by the comparator IZA-2 and other means. X-ray irradiation of crystals was carried out on a standart device URS-55 equipped with an X-ray tube with a copper anode and operating parameters $U=40 \mathrm{~kW} I=10$ MA. The power of the radiation dose at the location of the 
crystals, according to the indications of the dosimeter KID-2, was $0.11 \mathrm{R} / \mathrm{s}$. The total sample irradiation time was $160 \mathrm{~min}$, corresponding to the radiation dose of $1057 \mathrm{R}$. For the optical experiment the spectrophotometer SP-26 was used. The investigated wavelength range was $200 \ldots 650 \mathrm{~nm}$. As a luminaire, the deuterium lamp DDS-30 was used with measurements in the spectral range $200 \ldots 350 \mathrm{~nm}$, and the incandescent lamp OP-33-0.3 with measurements in the range $350 \ldots 650 \mathrm{~nm}$. For the whole range of measurements, an antimony-cesium photocell F-17 was used as a photodetector of radiation. All experiments were carried out at a constant temperature $T=300 \mathrm{~K}$.

\section{RESULTS AND DISCUSSION}

Figure shows the measurement results of spectral coefficients of transmission $\tau_{\lambda}$ at wavelengths range $220 \ldots 650 \mathrm{~nm}$ on LiF crystals having a residual deformation of $3.3 \%$ at the irradiation dose $\xi$ range of $0 \ldots 1057 \mathrm{R}$ [1]. As it can be seen from Fig. for unirradiated crystals the value $\tau_{\lambda}$ monotonously increase with the increase of the wavelength (curve 1). In the case of crystal irradiation with the dose of $400 \mathrm{R}$ the curve $\tau_{\lambda}(\lambda)$ remains virtually unchanged, but the transmittance capacity of samples is significantly reduced (curve 2).

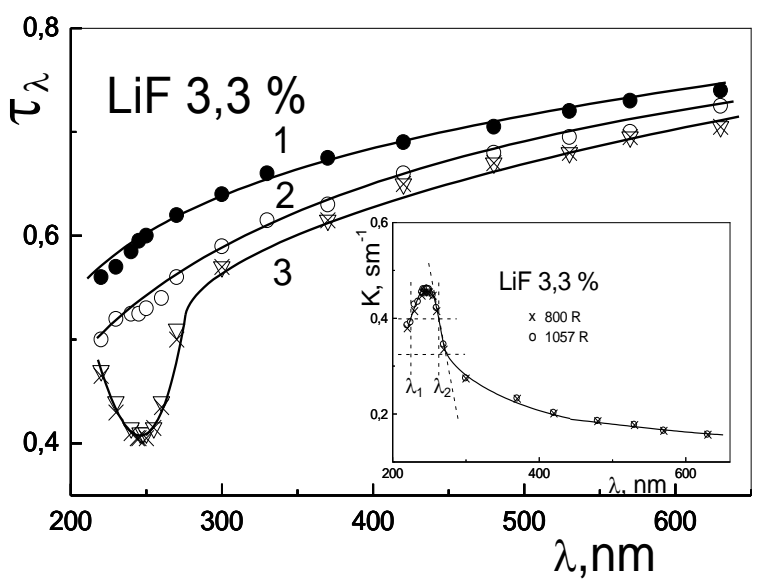

Dependences of the spectral transmittance coefficient of the wavelength in LiF crystals on different doses $\xi$ of irradiation [1]: curve 1-unirradiated crystal; 2 -irradiation dose of $400 R ; 3$ - irradiation dose of $800 R$

(points $\nabla)$ and $1057 R$ ( point $X)$; insert page - dependences of the attenuation index on the wavelength

in crystals LiF with $\varepsilon=3.3 \%$ for the irradiation doses of 800 and $1057 R$, also taken from [1]

With the increase of the radiation dose up to $800 \mathrm{R}$ (curve 3 -experimental points marked $\nabla$ ) a pronounced absorption band has been observed (see Figure insert page), which corresponds to the minimum on the curve $\tau_{\lambda}(\lambda)$, which lies at a wavelength of approximately $248 \mathrm{~nm}$. At other segments of the wavelength, the mode of dependence $\tau_{\lambda}(\lambda)$ does not change. The indicated character of curve $\tau_{\lambda}(\lambda)$ behavior is preserved even in the case that a dose of X-ray irradiation is increased to 1057 (see curve 3 - experimental points are marked $\times$ ). The presence of the absorption bands indicates the presence of color centers in crystals. Since for ionic crystals the bands borders are fairly well researched, it is possible to mark, that in the measured samples there are clearly presented, having the simplest configuration, electronic color centers - F-centers, the minimum on the curve $\tau_{\lambda}(\lambda)$ (for which the maximum of the attenuation) is at the wavelength $\lambda_{\max } \approx 248 \mathrm{~nm}$ [25]. It has been also noted that there is no evidence for the presence of $\mathrm{F}_{2}$ and $\mathrm{F}_{3}$-centers in samples the given curves do not show, as in the vicinity of $\lambda_{\max } \approx 443 \mathrm{~nm}$ for $\mathrm{F}_{2}$-centers and $\lambda_{\max } \approx 307$ and $377 \mathrm{~nm}$ for different types of $\mathrm{F}_{3}$-centers [25] there have not been found any nonmonotonicies. This corresponds well to the results of the authors [26] that have used small doses of X-rays for LiF, that have been produced at the same X-ray unit in the regime close to ours, and, as in the present study, only F-centers have been observed.

It is known that in the presence of dependences $\tau_{\lambda}(\lambda)$ and the known spectral density of the radiation flux from the source of radiation we can make the equation of radiation colority [28]:

$$
D=x^{\prime} \cdot X+y^{\prime} \cdot Y+z^{\prime} \cdot Z,
$$

where $X, Y, Z$ - the main colors of the colorimetric system, and $\mathrm{x}^{\prime}, \mathrm{y}^{\prime}, \mathrm{z}^{\prime}-$ the color's coordinates; $x^{\prime}+y^{\prime}+$ $z^{\prime}=m-$ color's module. Colority coordinates $x, y, z$ can be by the formulas:

$$
x=\frac{x^{\prime}}{m}, y=\frac{y^{\prime}}{m}, z=\frac{z^{\prime}}{m} .
$$

Apparently, that to form the equation of color, that penetrates through the crystal (1) and in order to calculate its colority (2) it is necessary to know the coordinates of the color.

Them, in their turn, one can define with he help of spectrophotometric method [29] by the formulas [2830]:

$$
\begin{aligned}
& x^{\prime}=\Delta \lambda \cdot \sum_{i=\lambda_{1}}^{\lambda_{n}} \varphi_{e \lambda i} \cdot \tau_{\lambda i} \cdot \bar{x}_{\lambda i} ; \\
& y^{\prime}=\Delta \lambda \cdot \sum_{i=\lambda_{1}}^{\lambda_{n}} \varphi_{e \lambda i} \cdot \tau_{\lambda i} \cdot \bar{y}_{\lambda_{i}} ; \\
& z^{\prime}=\Delta \lambda \cdot \sum_{i=\lambda_{1}}^{\lambda_{n}} \varphi_{e \lambda i} \cdot \tau_{\lambda i} \cdot \bar{z}_{\lambda i},
\end{aligned}
$$

where $\bar{x}_{\lambda i}, \bar{y}_{\lambda i}, \bar{z}_{\lambda_{i}}-$ the specific tristimulus values; $\varphi_{e \lambda i}-$ spectral radiation flux density of the source; $\Delta \lambda$ - calculation phase, that for most cases provides sufficient precision when $\Delta \lambda=10 \mathrm{~nm}$.

Taking into account that in the spectral measurements in the interval $350 \ldots 620 \mathrm{~nm}$ as a luminaire in the spectrophotometer SP-26 used the incandescent lamp OP-33-0.3, which can be considered as a source of type A, using standart table values [30], which specify the behavior characteristics $\varphi_{e \lambda i}, \bar{x}_{\lambda i}, \bar{y}_{\lambda i}, \bar{z}_{\lambda i}$ in visible spectrum. The calculation was made for spectral range $380 \ldots 620 \mathrm{~nm}$ in the Excel program for the curves $\tau_{\lambda}(\lambda)$ in Figs. occupying the uppermost position ( $\xi=0 \mathrm{R})$ and the extreme lower position $(\xi=1057 \mathrm{R})$. 
As a result of complex calculation of optical and lighting parameters we can note the following. Reduction of $\tau_{\lambda}$ approximately 1.1 times at transition from values of irradiation doses $\mathrm{s}$ of crystals $\xi=0 \mathrm{R}$ to $\xi=1057 \mathrm{R}$ causes a decrease of color coordinates in the same value $x^{\prime}, y^{\prime}, z^{\prime}$ and brightness of a basic color of radiation $L=683 \cdot y^{\prime}$, passing through the investigated medium by a similar magnitude of coordinates and it is described by the equation (1). As to the color characteristics of the radiation passing through the investigated crystals with different mechanical state, they remain unchanged $-x \approx 0.44 ; y \approx 0.41$; which holds on a constant level such characteristics as $\lambda^{*} \sim 570 \mathrm{~nm}$ (dominant wavelength ) and $P \sim 5 \%$ (color purity).

Thus, it can be verified that the irradiation changes of the studied crystals in the interval of irradiation doses $0 \ldots 1057 \mathrm{R}$ in no way reflected in the change in color (spectral composition) of radiation of the visible region of the spectrum passing through the crystal.

\section{CONCLUSIONS}

It has been found that with increasing of irradiation dose in the interval $0 \ldots 1057 \mathrm{R}$ in LiF samples, the spectral curves $\tau_{\lambda}(\lambda)$, and characteristics $\mathrm{x}^{\prime}, \mathrm{y}^{\prime}, \mathrm{z}^{\prime}, L$, as well change monotonously. In the tested interval of irradiation doses, increase in dose $\xi$ leads to the some reduction of these parameters for about 1.1 times, but at the same time, the change in $\xi$ in the interval $0 \ldots 1057 \mathrm{R}$ does not affect the color of the radiation of radiation of the visible region of the spectrum passing through the crystal. The indicated result may appear to be of interest for applied optics (lighting engineering, colorimetry, photometry) and physics of devices, elements and systems.

\section{REFERENCES}

1. G.A. Petchenko, S.S. Ovchinnikov. Effect of the preliminary deformation and irradiation on the optical absorption in LiF crystals // Problems of Atomic Science and Technology. Series "Physics of Radiation Effect and Radiation Materials Science”. 2014, N 2(90), p. 2933.

2. G.A. Petchenko, A.M. Petchenko. Dependence of electronic color center concentration on the state of irradiated LiF crystal dislocation structure // Problems of Atomic Science and Technology. Series "Physics of Radiation Effect and Radiation Materials Science". 2015, N 2(96), p. 25-28.

3. G.A. Petchenko, A.M. Petchenko. The study of the dislocation resonance in $\mathrm{LiF}$ crystals under the influence of the low-dose X-irradiation // Functional Materials. 2010, v. 17, N 4, p. 421-424.

4. G.O. Petchenko. Acoustic studies of the effect of $\mathrm{X}$-ray irradiation on the dynamic drag of dislocations in LiF crystals // Ukrainian Journal of Physics. 2011, v. 56, N 4, p. 339-343.

5. G.A. Petchenko. The investigation of the dislocations resonant losses of ultrasonic sound in irradiated LiF single crystals in the interval of irradiation doses 0...400 P // Problems of Atomic Science and Technology. 2012, N 2(78), p. 36-39.
6. G.A. Petchenko. Dynamic damping of dislocations in the irradiated LiF crystals // Functional Materials. 2012, v. 19, N 4, p. 473-477.

7. G.A. Petchenko. The study of the dynamic and structure characteristics in irradiated $\mathrm{LiF}$ crystals // Problems of Atomic Science and Technology. 2013, N 2(84), p. 55-59.

8. G.O. Petchenko, O.M. Petchenko. Research of the elastic wave velocity dispersion in X-rayirradiated LiF crystals // Ukrainian Journal of Physics. 2013, v. 58, N 10, p. 974-979.

9. T. Suzuki, A. Ikushima, M. Aoki. Acoustic attenuation studies of the frictional force on a fast moving dislocation // Acta Met. 1964, v. 12, N 11, p. 1231-1240.

10. Kh.M. Khalilov, A.I. Agaev. Ultrasound absorption in $\mathrm{KCl}$ single crystals in the megahertz frequency range // Izv. AN Azerbajdg. SSR. 1966, N 2, p. $82-86$.

11. Kh.M. Khalilov, A.I. Agaev. Dislocation absorption of ultrasound in deformed $\mathrm{KCl}$ crystals // FTT. 1971, v. 9, N 9, p. 2729-2731.

12. I.V. Gectina, F.F. Lavrentiev, V.I. Startsev. Temperature dependence of the viscous drag coefficient of dislocations in zinc crystals // Physics of Metals and Metallography. 1974, v. 37, N 6, p. 1274-1277.

13. E.V. Korovkin, Ya.M. Soifer. The effect of dislocations on the attenuation of ultrasound in $\mathrm{NaCl}$ crystals // FTT. 1971, v. 13, N 12, p. 3709-3710.

14. N.P. Kobelev, Ya.M. Soifer. Viscous drag of dislocations in alkali halide crystals // FTT. 1976, v. 18, N 4, p. 1073-1076.

15. R.M. Stern, A. Granato. Damped dislocation resonance in copper // Internal friction and defects in metals. M.: "Metallurgiya", 1965, p. 149-191.

16. A. Granato, K. Lücke. String model of dislocation and dislocation ultrasound absorption. Physical Acoustic, v. 4, p. A. M.: "Mir", 1969, p. 261-321.

17. V.I. Alshits, V.L. Indenbom. Dynamic drag of dislocations // Usp. Fiz. Nauk. 1975, v.115, N 3, p. 3-39 (in Russian).

18. V. Naundorf, K. Lücke. Mechanisms of Internal Friction in Solids. M.: "Nauka", 1976, 91 p.

19. F. Fanti, J. Holder, A.V. Granato. Viscous drag on dislocation in $\mathrm{LiF}$ and $\mathrm{NaCl} / /$ J. Acoust. Soc. Amer. 1969, v. 45, N 6, p. 1356-1366.

20. A.V. Granato, J. de Clerk, R. Truell. Dispersion of elastic waves in sodium chloride // Phys. Rev. 1957, v. 108, N 3, p. 895-896.

21. A.M. Petchenko, G.A. Petchenko. Features of resonance absorption of longitudinal ultrasound in strained crystals $\mathrm{KBr}$ at temperature variations // Functional Materials. 2007, v. 14, N 4, p. 475-479.

22. O.M. Petchenko, G.O. Petchenko. Phonon drag of dislocations in $\mathrm{KCl}$ crystals with various dislocation structure states // Ukrainian Journal of Physics. 2010, v. 55, N 6, p. 716-721.

23. O.M.M. Mitchel. Drag of dislocation in LiF // J. Appl. Phys. 1965, v. 36, N 12, p. 2083-2084.

24. A. Smakula. Uber Erregung und Entfarbung lichtelektrisch leitender Alkalihalogenide // Z. Physik. 1930, N 9-10(59), p. 603-614. 
25. V.M. Lisitzyn. Radiation solid state physics. Tomsk: "Izdatelstvo Tomskogo Politekhnicheskogo Universiteta", 2008, 172 p. (in Russian).

26. M.V. Galustashvili, M.G. Abramishvili, D.G. Driaev, V.G. Kvachadze. Effect of magnetic field on the radiation hardening LiF crystals // FTT. 2011, N 53(7), p. 1340-1342.

27. I.M. Nekludov, A.K. Malik, A.A. Parkhomenko, A.V. Rudnitskiy. Ionization mechanisms of radiation-induced defects' generation in LiF crystals irradiat- ed with high-energy electrons. // Problems of Atomic Science and Technology. 2009, N 2(93), p. 52-56.

28. V.V. Meshkov. The basics of lightning engineering. M.: "Energiya", 1979, 368 p.

29. M.M. Gurevich. Photometry (Theory, methods and devices). L.: "Ehnergoatomizdat", 1983, 272 p.

30. State Standart "GOST" 7721-89. The illuminants for color measuring. Types. Specifications. Designation. M.: "Standarts publishing house", 1989.

Article received 10.02.2020

\title{
ОПТИЧЕСКИЕ И КОЛОРИМЕТРИЧЕСКИЕ ХАРАКТЕРИСТИКИ ПРОДЕФОРМИРОВАННЫХ КРИСТАЛЛОВ LiF ПОД РЕНТГЕНОВСКИМ ОБЛУЧЕНИЕМ
}

\author{
А.М. Петченко, Г.А. Петченко, С.Н. Бойко, А.В. Безуалый
}

Исследовано влияние пластической деформации на оптические характеристики кристаллов LiF и колориметрические характеристики оптического излучения, проходящего через кристаллы с разными дозами облучения. Установлено, что изменение дозы облучения в интервале $0 \ldots 1057$ Р приводит к уменьшению по абсолютной величине координат цвета и яркости излучения, проходящего через кристалл, но цветность излучения при этом не изменяется.

\section{ОПТИЧНІ І КОЛОРИМЕТРИЧНІ ХАРАКТЕРИСТИКИ ПРОДЕФОРМОВАНИХ КРИСТАЛІВ LiF ПІД РЕНТГЕНІВСЬКИМ ОПРОМІНЕННЯМ}

\section{О.М. Петченко, Г.О. Петченко, С.М. Бойко, А.В. Безуглий}

Досліджено вплив рентгенівського опромінення на оптичні характеристики кристалів LiF i колориметричні характеристики оптичного випромінювання, що проходить через кристали з різними дозами опромінення. Встановлено, що зміна дози опромінення в інтервалі 0...1057 Р призводить до зменшення за абсолютною величиною координат кольору і яскравості випромінювання, що проходить через кристал, але кольоровість випромінювання при цьому не змінюється. 